\title{
O mundo antigo visto por lentes contemporâneas: as extremas direitas na França nas décadas de 1980 e 90, ou da instrumentalidade da Antigüidade
}

\author{
Glaydson José da Silva*
}

Resumo: Este trabalho analisa os usos dos estudos sobre o mundo antigo pelas extremas direitas francesas como forma de estabelecer compreensões do mundo contemporâneo, visando à legitimação de direitos advindos da idéia de origem. Propõe uma reflexão acerca do papel do passado nos jogos de estratégia e afirmações identitárias com base na instrumentalização levada a termo pelos grupos analisados (GRECE, Front National e Terre et Peuple). Parte da premissa de que o saber sobre o passado, sua e escrita e suas leituras são poderes e geram poderes.

Palavras-chave: Instrumentalização da Antiguidade, Extremas Direitas, Usos do Passado.

A História como disciplina talvez nunca tenha experimentado tantas mudanças como as por ela vividas desde os anos trinta do século passado. A História Antiga, mais que as outras apegada à tradição, nem sempre acompanhou de perto essas mudanças, contudo, esse distanciamento das metamorfoses do meio não foi uma regra. A História da Antigüidade Clássica, e do mundo antigo de maneira geral, foi acompanhada, ao longo dos últimos anos, principalmente a partir do início da década de 1990, de grandes mudanças ocorridas nos domínios da História. O estudo das relações entre a Antigüidade e o mundo contemporâneo, entre o passado e o presente na escrita da História do mundo antigo tem sido, desde então, objeto de inúmeros estudos, e tem contribuído para o desenvolvimento de uma História Antiga que se pretende mais problematizada.

Há pouco ainda considerada como muito propensa a se fechar em suas próprias fronteiras ${ }^{1}$ e pouco dada à interpretação, ${ }^{2}$ a História da Antigüidade tem produzido, hoje, muitos e diferentes trabalhos, que têm por objetivo melhor compreender as tênues relações entre o passado estudado e o presente vivido por seus intérpretes. Em uma ampla perspectiva, esses trabalhos têm se pautado por uma análise na qual seus objetos não se desvinculam de suas tradições histórico-interpretativas. Nesse sentido, não raro a Antigüidade tem sido percebida a serviço de uma certa lógica justificadora e legitimadora, onde se pôde ver, ao longo do século XX, suas ligações com as questões 
identitárias nacionais, com os regimes autoritários, com o racismo, com o machismo e com práticas políticas e sociais de toda sorte; contudo, o estudo da Antigüidade Clássica não precisa reforçar preconceitos nem constituir-se em elemento de opressão. ${ }^{3}$ Essa consideração pode ser estendida aos estudos do mundo antigo, de modo geral. Um olhar armado criticamente pode evidenciar uma certa instrumentalidade da História Antiga e sugerir que o debate a respeito das relações entre o passado e o presente deve, também, fazer parte das pesquisas nesse campo, alargando seu universo de temas e abordagens.

Os estudos sobre o presente, que tiveram como escopo o mundo antigo, evidenciaram e evidenciam um caráter marcadamente discursivo a respeito da Antigüidade, que por vezes foi inventada para atender aos interesses daqueles que reivindicavam uma certa herança antiga, os seus beneficiários. Como observa Roger-Pol Droit, 4 “de Renascença em Renascença a Europa inventou todas as sortes de Antigüidade” . Tendo como recorte temático o universo político direitista na França das últimas décadas, tem-se por objetivo nesse texto analisar a presença da Antigüidade no discurso político das extremas direitas como forma de legitimação de direitos (políticos), advindos dos direitos (étnicos) de origem.

A ascensão dos grupos políticos de extrema direita na Europa é um fenômeno político de desenvolvimento marcado, principalmente, pelo contexto do pós-guerra, ${ }^{5}$ intensificado pela década de 1980 e pela queda do Comunismo. ${ }^{6}$ De designações diversas, esses grupos de radicalização política, comumente, aproximaram-se e se aproximam, em suas propostas, de vertentes nacionalistas (e, mesmo, europeístas) e xenófobas. A Antigüidade Clássica (mas não só), não raro, esteve na origem das justificativas dessas propostas. No caso da França, os usos do passado indo-europeu, grego, romano e gaulês atenderam e atendem a uma certa instrumentalidade política por parte de círculos como o GRECE - Groupement de Recherche et d'Étude pour la Civilisation Européenne, partidos nacionalistas como o Front National e grupúsculos direitistas como o articulado em torno da revista Terre et Peuple.

Na atualidade, a utilização da História do mundo antigo como instrumento legitimador do ideário de grupos políticos, particularmente grupos políticos conhecidos como de extrema direita, é algo recorrente e que dispõe, ainda, de poucas produções científicas especializadas a respeito. Na França, país de longa tradição na área dos estudos da Antigüidade, onde o ensino de História foi fortemente determinado pelo ideário do Estado Nação, a produção historiográfica acerca do mundo antigo sempre esteve presente e desempenhou grande papel nos jogos políticos. Isso em parte pelo 
lugar privilegiado que os estudos do mundo antigo ocupam nas sociedades ocidentais, de modo geral, mas, também, devido às possibilidades de paralelos que a História da Antigüidade pôde e pode oferecer às sociedades modernas, hoje. ${ }^{7}$ Essa instrumentalidade do mundo antigo é um dos grandes pilares de sustentação da legitimidade das propostas xenófobas e racistas dos grupos em questão. Compreender essas apropriações e instrumentalidades requer pensar esses grupos no seio de sua formação, percebendo-os ligados, em sua origem, à matriz direitista do pós-Segunda Guerra na França.

Desde meados da década de oitenta a oeste e desde a queda do Comunismo a leste, a Europa conheceu

um fenômeno de radicalização política que os observadores (politólogos, sociólogos, historiadores, jornalistas etc.) designam por nomes diversos. Fala-se de "ascensão da extrema direita” ou da "direita radical”. Evoca-se a irresistível ascensão do "populismo" ou do "nacional populismo" sem sempre precisar se esses termos se aplicam a movimentos, programas, personalidades ou regimes oriundos de matriz direitista ou esquerdista. ${ }^{8}$

De imprecisão semântica, como os vocábulos direita e esquerda, os grupos de radicalização política conhecidos como de extrema direita são designados como de ultra-direita, direita extraparlamentar, direita da direita, direita radical, etc. Esses termos não revelam, contudo, pela parte dos articulistas, “mais que uma necessidade de evitar repetições”. ${ }^{9}$ A diversidade de designações se traduz, então, numa certa dificuldade de definir, com precisão, o objeto examinado. Como a direita, a extrema direita não constitui uma entidade homogênea. Por longo tempo distinta de muitas outras correntes do universo direitista pela sua "recusa absoluta das instituições democráticas e pela violência de seu comportamento" ${ }^{10}$ essas características não mais definem a extrema direita, hoje, nos países onde a democracia liberal está de longa data enraizada nas instituições e nos espíritos. De cultura conservadora e autoritária (antiigualitária), levada a limites radicais, caracterizada pelo populismo, pelo nacionalismo étnico e pela xenofobia, muitas vezes ligada aos ideais do Nazismo e do Fascismo, as extremas direitas do pós-Segunda Guerra, na França serão associadas à “Nouvelle Droite”. Essa expressão foi comumente utilizada nos meios especializados a partir de 1978 para designar o GRECE, mas, por extensão, para se referir, desde 1979, ao conjunto formado pelo GRECE e pelo Club de l'Horloge. ${ }^{11}$ Contudo, um uso pouco recorrente, mas que conheceu uma certa difusão, é aquele que designa, por esse nome, as direitas francesas do pós-guerra. É em torno da “Nouvelle Droite” que se organizarão muitos intelectuais, estudantes, políticos, etc., que, ligados a uma concepção de História, de civilização e de 
homem muitíssimo específica, irão ler a História nacional, numa prática historiográfica onde a História da Antigüidade está marcadamente comprometida com ideologias de justificação e legitimação de direitos e de desigualdades raciais e de classe. A "Nouvelle Droite” ideológica é

constituída ao longo dos últimos anos de elementos muito díspares - revistas, círculos de pensamento, colóquios, personalidades implicadas em partidos e organizações autônomas; [ela] não é filha nem da crise que afetou as economias dos países industriais a partir de 1974 - ainda que sua emergência na mídia se inscreva em um contexto de retorno à Guerra Fria e do marasmo persistente - nem da relação com os eventos de 1968. Ela é diretamente oriunda do desempenho que tem, após o choque de 1962, um certo número de militantes engajados que gravitam ao redor do Europe-Action, a revista e o círculo animados por Dominique Venner e Jean Mabire e a Federação dos Estudantes Nacionalistas. Para esses militantes, em sua maioria de menos de 30 anos, o jogo é, primeiramente, ideológico. ${ }^{12}$

Criado em 1963 e ligado umbilicalmente ao surgimento da "Nouvelle Droite”, o grupo Europe-Action terá uma curta trajetória intelectual, marcada pelas suas convicções europeístas e fortemente nacionalistas e pela fundamentação do racismo biológico em bases científicas. O grupo se pretende uma ruptura na História da direita francesa. Para seus membros, coordenados por Dominique Venner e Jean Mabire,

a extrema direita não inventou nada de novo desde a guerra. Ela se encontra no meio de um cemitério de idéias. ... Suas legiões esqueléticas se dividiram com o sentimento confuso de um debate de outra época. ... o mundo mudou e é talvez chegado o momento de inventar uma outra coisa. $^{13}$

Venner explicava que só uma nova elaboração doutrinal podia constituir uma "resposta ao fracionamento infinito das direitas" e, sobretudo, que ela necessitava “combater mais pelas idéias e pela astúcia que pela força”,14 numa perspectiva de recusa de "uma solução ativista” em favor de um combate "sobre o plano legal”. O racismo é, nesse domínio, um dos principais focos do Europe-Action. ${ }^{15}$

De perspectiva doutrinal muito similar à do Europe-Action e composto essencialmente por seus antigos membros, é declarado na prefeitura de Nice, em janeiro de 1969, o GRECE, onde se encontra aquele que brevemente se tornará a principal referência teórica da “Nouvelle Droite”, Alain de Benoist. De constituição intelectual marcada por uma cultura racista, neonazista e neofascista, onde a exaltação do "nacionalismo europeu”, fundada sobre a primazia da raça branca, é o grande leitmotiv, será o GRECE que irá publicar as revistas Nouvelle École e Élements, publicações de caráter doutrinal do grupo. 
Para Benoist, “a (re)elaboração do 'nacionalismo europeu’ se esforçará por dar à defesa de uma identidade européia culturalmente não misturada uma base universalizaste״16; além de Benoist, outras personalidades conhecidas do universo intelectual francês da direita comporão o grupo, como: Roger Lemoine, Dominique Venner, Jean Mabire, Pierre Vial, Dominique Gajas, etc.

Como o Europe-Action e o GRECE, em uma lógica intelectual muitíssimo similar, será fundado em 1974 o Club de l’Horloge, que marcará a História da “Nouvelle Droite” francesa no final década de 1970. É dessa “Nouvelle Droite” de pensamentos conflitantes, ideologias nem sempre homogêneas, mas fundadas em bases comuns, que se alimentará o pensamento “direitista” sobre o mundo antigo nas décadas de 1980 e 90 . O universo conceitual da "Nouvelle Droite" se organiza em torno de um certo número de temas, cujo mais importante, porque ocupa o centro da construção, é aquele do "mito igualitário". ${ }^{17}$ Personalizada, é em torno de Alain de Benoist e de sua crítica à igualdade social que a "Nouvelle Droite” se organizará. ${ }^{18}$ A respeito dessa desigualdade diria Benoist:

\begin{abstract}
A meus olhos, o inimigo não é "a esquerda” ou “o Comunismo”, ou, ainda, "a subversão”, mas, bem ou mal, esta ideologia igualitária, cujas formulações, religiosas ou laicas, metafísicas ou pretensamente "científicas", não cessaram de florir desde dois mil anos, cujas "idéias de 1789" não foram mais que uma etapa e cuja subversão atual e o Comunismo são a inevitável conseqüência. ${ }^{19}$
\end{abstract}

Do trabalho de etólogos e geneticistas Benoist e seus partidários deduzem que o homem, sendo um animal

..., não tem nenhuma razão de pensar que ele não é portador, como todos os outros animais, de um patrimônio genético que condiciona muito fortemente sua inteligência, suas pulsões, sua sensibilidade, sua moralidade. ${ }^{20}$

Daí para práticas eugênicas fundadas no “realismo biológico”, legitimadas pela Etologia, pela Genética, pela História etc., a distância não é muito grande. Para Benoist, “O realismo biológico é a melhor ferramenta contra as quimeras idealistas”. ${ }^{21}$ As teorias de Georges Dumézil sobre a “tripartição sócio-funcional”, característica das sociedades indo-européias serão, aí, muitíssimo utilizadas. Para a “Nouvelle Droite”, é clara a existência de uma “cultura indo-européia”, que transcende os Estados-nações, biologicamente determinada e "conforme as leis gerais do vivente”. ${ }^{22}$

A referência aos indo-europeus permite conferir uma origem comum aos povos europeus e justifica sua união imperial. Tira-se dos estudos de Dumézil sobre a 
existência de um substrato lingüístico indo-europeu a idéia da existência de uma raça indo-européia, logo, de uma "herança” e de uma mentalidade "indo-européia”, ligada às noções de língua, povo e pátria originais, o que conduz, conseqüentemente, às idéias de superioridade racial original. ${ }^{23} \mathrm{O}$ GRECE publicará, na seção L'Itinéraire, do número 21-22 da Nouvelle École (jan.-fev 1973), um dossiê consagrado a esse tema com o título “George Dumézil et les études indo-européennes”. A introdução é de Alain de Benoist, que a assina com o pseudônimo N.E. O retorno aos ancestrais é, então, aos olhos de Benoist e da "Nouvelle Droite”, o reencontro com a religião, a ideologia e a organização dos povos indo-europeus.

\begin{abstract}
A única resposta positiva [grifo no original] aos problemas, aos desafios de nosso tempo, está numa atitude que reproduziria, adaptando e reinventando, aquela mesma dos indo-europeus diante da revolução neolítica ... A herança indo-européia que nós reencontramos e cultivamos em nós mesmos, nós a projetamos, então, duplamente na História, como representação do passado e como "imaginação do futuro. ... quando nós falamos de tradição indo-européia, ou quando trazemos à luz do dia os traços esquecidos do mito, da religião, da ideologia e da História dos povos nos quais nós queremos reconhecer nossos ancestrais, nós não olhamos somente para trás. Ao contrário, como Janus, nós vislumbramos também o futuro. ${ }^{24}$
\end{abstract}

Essa “nostalgia” dos indo-europeus se apropriará muitíssimo dos trabalhos de Dumézil. O aparecimento, no começo da década de 1980, de duas obras de Jean Haudry (L'Indo-Européen e Les Indo-européens, PUF 1980-1981) é bem representativo da atualidade das apropriações históricas da Antigüidade indo-européia feitas pela “extrema direita”. Haudry é professor na École Pratique des Hautes Études e na Université de Lyon III, tendo sido, também, membro do Conselho Científico do Front National. Lyon III é conhecida por agrupar um grande número de professores, universitários e grupos direitistas. ${ }^{25}$ Referenciados na bibliografia por títulos produzidos por institutos nacionais socialistas sob o Reich (como os do “raciólogo” Hans Günther), os trabalhos de Haudry foram contundentemente criticados no meio historiográfico. ${ }^{26}$

Como observa Olivier Dumolin, “A manipulação das conclusões históricas, arqueológicas e lingüísticas sobre os indo-europeus oferece um caso representativo da distorção dos resultados da pesquisa em proveito de uma renovação cultural da direita”. ${ }^{27}$ Para esse autor, esse ressurgimento da utilização das ciências filológicas, históricas e arqueológicas para fins racistas contribuiu, sem dúvida, para relançar uma velha polêmica sobre as simpatias presumidas da extrema direita de Dumézil, particularmente no fim dos anos trinta (383). Maureice Olender $^{28}$ insere os trabalhos de Haudry "no 
conjunto dos trabalhos intelectuais onde a erudição quer legitimar afirmações de tipo arqueológico, antropológico ou lingüístico sobre as origens indo-européias”.

Percebendo a Europa cristã como “a maior empresa de “aculturação” que a humanidade já conheceu “29 o GRECE, nas trilhas da "Nouvelle Drotie”, difundirá a necessidade de um retorno a 30 uma espécie de reencontro com a "Europa”, no restabelecimento da ordem "normal” das coisas. Como observa Milza:

é necessário, por um retorno às fontes do pensamento antigo, suprimir a distinção entre o humano e o divino, característica da tradição judaico-cristã. Fazendo do Deus único um ser distinto de natureza superior ao homem, as religiões reveladas introduziram no mundo os germes da intolerância e do totalitarismo. O retorno ao espírito do paganismo não mais fará que recusar um e outro desses desvios. ${ }^{31}$

“O totalitarismo era, nas origens, absolutamente contrário à mentalidade dos indo-europeus.” 32 É nesse ideário que se encaixam as propostas do GRECE e sua ética,

sem moral absoluta, universal, válida para todos os tempos e para todos os países, assim, sem "direitos do homem” no sentido humanista do termo, mas uma ética utilitária, liberada de toda referência paralisante ao pecado, e, assim, o fim supremo seria o vencimento de si mesmo. Assim poderia se desenhar o "super-homem", que Alain de Benoist define não como um "superman de grandes bíceps ou grande QI", mas como aquele que "se coloca em situação "heróica” de vencer a si mesmo" e se aplica a permanecer fiel à norma que está fixada. ${ }^{33}$

Numa perspectiva antiigualitária, em sua ótica à imagem da natureza e da História, o GRECE concebe sua visão de homem e de mundo, percebendo que as culturas são diferentes e dão respostas diferentes às questões essenciais. ... toda tentativa de unificá-las termina por destruí-las ...” ${ }^{34}$. Essa lógica intelectual do GRECE atravessará toda a década de 1980 e, ainda hoje, define as proposições do grupo. Uma percepção muito erudita da atualidade do ideário do GRECE pode ser vista nas análises de Pierre André Taguieff ${ }^{35}$ e de Pierre Milza. ${ }^{36}$ É do GRECE que sairá a matriz ideológica do Front National e do grupo Terre et Peuple.

Três anos após a criação do GRECE constitui-se, em 1972, em torno de JeanMarie Le Pen, o Front National. Conhecido hoje como a maior organização francesa da extrema direita, o Front National, à época de sua criação, apresentava-se como uma força aglutinadora dos grupos direitistas. ${ }^{37} \mathrm{O}$ partido que no primeiro turno das eleições de abril-maio de 2002 derrotou o primeiro ministro socialista Leonel Jospin, com um recorde histórico de votos válidos da extrema direita (17\%) para seu candidato, JeanMarie Le Pen, era incipiente na eleição presidencial de 1974, quando obteve 0,74\% dos votos válidos. Para Michel Winock, Le Pen "vegeta por longo tempo à frente de um grupúsculo”. ${ }^{38}$ 
Se por um lado o GRECE reivindica para si o pertencimento a uma "Nouvelle Droite”, o Front National recusará, veementemente, sua designação como partido de extrema direita ${ }^{39}$ e, mesmo, de direita. Contudo, recusar o epíteto não o exime de sua classificação, consensual entre os especialistas do tema, em um campo de estudos delineado. Eleita uma das principais frentes do discurso político do partido, a imigração se inscreve no mais atual e, talvez, no mais complexo aspecto das discussões identitárias na França, hoje; a ela recorrentemente são associados, pelos partidos de direita, problemas como: falta de segurança pública, desemprego, saúde e decadência moral. ${ }^{40}$ Enfim, a velha noção de crise social, característica dos discursos de direita. Em conformidade com uma certa tipologia dos discursos sobre crise da ordem e perda de valores, o tema da decadência se articula em torno de três pontos: uma constatação, uma análise das causas e uma apresentação dos remédios. ${ }^{41}$

A imigração está no cerne dos debates políticos da extrema direita, visto constituir essa "invasão estrangeira”, a seus olhos, uma verdadeira ameaça à identidade nacional. Como observa indignado Le Pen, a respeito da concessão “indistinta” e “incontrolada” da cidadania francesa, La carte d'identité n'est pas la carte orange. ${ }^{42}$ É, ainda, nas palavras de Jean-Marie Le Pen que se percebe, de modo manifesto, pelo olhar das direitas, o grande perigo que os imigrantes oferecem em relação à identidade nacional: “Acuso nossos adversários de serem cúmplices de um verdadeiro genocídio político, pois tomar a um povo sua identidade é tomar uma grande parte de sua alma”.

Na linguagem do Front, é necessário chamar um gato, um gato; chamar de francês, um francês.

\begin{abstract}
Nós estamos em um novo período de imigrações. Jamais, sem dúvida, os povos foram, como outrora, atraídos pelas riquezas do Ocidente como no Império Romano. É necessário lembrar que essas "grande invasões” são estudadas na Alemanha sob o nome de "grandes imigrações". Sabemos o que elas trouxeram para o Império romano. As imigrações, mão-de-obra solicitada nos anos 70 por um patronato que queria ganhar sempre mais e sub-remunerar os trabalhadores em lhe opondo uma concorrência estrangeira, são transformadas em imigrações de povoamento no momento em que o país deveria parar os fluxos vindos do sul. Para limitar a impressão negativa da modificação do tecido nacional, nacionaliza-se indistintamente. Roma tentou a mesma coisa ao se unir aos povos que vinham se instalar no Império. Roma caiu. Parece, decididamente, impossível tirar lições objetivas da História cega de todos os tempos pelas ideologias dominantes. ${ }^{43}$
\end{abstract}

Diretamente ligada à perda da identidade nacional e aos problemas do país, a imigração percebida pelo Front National é, antes de mais, representativa do medo diante do estrangeiro, do "desconhecido”, manifesto num sentimento de suspeição em face do imigrante. Para Riva Kastoryano ${ }^{44}$, os debates sobre a imigração e a cidadania 
traduzem, incontestavelmente, “a apreensão da classe política e da opinião pública de ver a nacionalidade 'dessacralizada' por uma cidadania por papéis, um direito desprovido de identidade”, e que coloca em risco o desaparecimento, por assimilação ou invasão, dos franceses d'abord.

No quadro diabólico da destruição da França ..., seguidos da extinção biológica ..., a submersão migratória ..., o desaparecimento da nação ..., o quarto lado é aquele do genocídio cultural. ${ }^{45}$

Como todos os grupos extremistas de direita, o Front National é crítico virulento do presente e vê, num retorno a um certo passado nostálgico, a única possibilidade de frear a decadência nacional, restabelecer os valores tradicionais e lutar e proteger, enfim, a "homogeneidade” da identidade francesa. Como observou Brigitta Orfali, o partido "não aparece como alguma coisa nova, à imagem do movimento ecológico, por exemplo, mas como uma revivescência do passado” ${ }^{46}$. Para o partido, a nação é, antes de mais, uma nação étnica, ligada a uma concepção organicista de uma terra que representa, antes de seu aspecto econômico, um forte apelo simbólico; ${ }^{47}$ a nação se funda, também, pela língua, pelo sangue e pelo pertencimento a uma França histórica, enfim, por um patrimônio comum:

O que nós temos de mais comum entre nós, aqui, hoje, e com nossos compatriotas franceses que estão no exterior deste recinto, é a noção de patrimônio, seu patrimônio cultural acumulado por séculos de trabalho e de sacrifícios, por gerações que nos precederam, seu imenso patrimônio moral cultural. ${ }^{48}$

A nação é a comunidade de língua, de interesse, de raízes, seus mortos, o passado, a hereditariedade e a herança. Tudo o que a nação lhe transmite no nascimento tem já um valor inestimável. ${ }^{49}$

É essa visão quase naturalista de nação que norteia os discursos sobre identidade nacional do Front, almejando um retorno a uma nação étnica e que se assenta num discurso de respeito à individualidade e a diferença, mas como fator de segregação.

Eu creio que a alquimia de nuanças caracteriza o homem branco da Europa ... Nós somos da mesma raça e do mesmo espírito. Nós respeitamos também o estrangeiro nessa universalidade da humanidade que faz de cada homem, de cada grupo ou nação um ser diferenciado. ${ }^{50}$

Em uma matéria de crítica aos manuais escolares franceses, publicada no National Hebdomadaire de $1^{0}$ de abril de 1987, pode-se ler, entre uma seleção de trechos dos principais manuais em uso, a seguinte frase: “é necessário compreender bem 
que uma nação é um futuro mosaico de comunidades” (Trata-se de um manual da editora Delagrave, cujo título não se encontra explicitado na matéria). O autor tem por objetivo expor as aberrações dos manuais escolares, estabelecendo um paralelo com a situação da educação no país.

Contrariamente ao GRECE, cuja instrumentalidade do mundo antigo é feita com o respaldado de sua leitura dos indo-europeus, o Front National fundamenta suas políticas xenofóbicas e segregacionistas na idéia de uma certa individualidade das nações, o que lhe confere uma leitura muito específica dos próprios mitos de origem franceses e, principalmente, da Gália e dos gauleses. Essa postura política do Front encontra-se enunciada já nos primórdios do partido, apegada aos ideais de uma França profunda. A respeito da imigração, seus clássicos bordões atravessam as décadas, a saber: “A França para os franceses”, “A invasão meteca”, etc. É nesse domínio que

a construção do real, a partir do enunciado “les français d'abord” implica uma retórica dicotômica específica que se funda sobre a oposição nós/eles ... Assim, os membros do Front National utilizam raramente o “eu”, mas dizem “nós”, “a França”, “os franceses”. ... oposição implícita ou expressa em seu mundo fechado: “os estrangeiros”, “eles” - ou seja, o mundo externo e ameaçador. ${ }^{51}$

A violência e o imigrante constituem, aí, os grandes temas do Front National e representam uma verdadeira simbiose, visto ser a primeira intrínseca ao segundo. Os referenciais da Antigüidade nesse domínio são vários. Nicole Loraux contra-argumenta com erudição os usos do conceito de democracia grega, contra os estrangeiros franceses, pelo Front National, por exemplo. Concordando com Finley, Loraux postula que nada, jamais, deve dispensar o historiador de explicar. ${ }^{52}$ Essa postura se volta para a necessidade da historiadora de combate intelectual contra o Front, ${ }^{53}$ no caso, contra a instrumentalização contemporânea do conceito de democracia ateniense como pretexto de exclusão dos imigrantes. Loraux analisa, nesse estudo, os usos dos "vinte e cinco séculos de tradição jurídica e política” feitos pelo partido como forma de obter uma autoridade discursiva sobre eleitores e parlamentares (Trata-se de uma crítica da historiadora a um discurso sobre democracia antiga proferido pela deputada MarieFrance Stirbois, do Front National).

Aproximando o pensamento de Jean-Marie Le Pen àquele de Aléxis Carrel, Lucien Bonnafé e Patrick Tort dirão:

O chefe da extrema direita francesa resolve, assim, um problema de "ascendência”, seguindo, nessa ordem, uma receita imemorial que preexiste, como a "ascendência" criada, que favorece ou garante o "ascendente”, ou seja, a empresa dominadora que o indivíduo ou grupo exerce sobre outros indivíduos ou grupos maiores. 
Para Le Pen e os militantes de seu partido,

a Biologia e a natureza são os quadros de explicação das relações ... onde o ser humano é um animal deveras específico, mas submetido às mesmas leis biológicas e naturais que os outros animais da "criação". 54

É da França de Vichy, com suas leis racistas, que retiram direitos tendo como pretexto a origem, que se inspira o partido. É da História, como grande campo de alusões e de suas relações com a "identidade nacional” que Le Pen extrai referências para seus discursos, estabelecendo paralelos com heróis (sobretudo Joana D’Arc) e atos fundadores da História nacional, criando uma França mítica da qual o partido tem necessidade e faz apelo na justificativa de suas posições ideológicas. A História da Gália, aqui, ocupa um lugar de destaque no discurso de constantes alusões históricas do Front. ${ }^{55}$ Como observa Anne-Marie Thiesse: Todo nascimento estabelece uma filiação. A vida das nações começa com a designação de seus
ancestrais. E a proclamação de uma descoberta: existe um caminho de acesso às origens, que
permite reencontrar os antigos fundadores e de recolher seus legados preciosos. ${ }^{56}$

Mito de fundação por excelência,

o mito gaulês é, como todo discurso mitológico sobre as origens, discurso sobre a identidade coletiva. Ele funciona, então, como um certo código cultural, e como tal, assume funções específicas, em oposição àquelas dos outros códigos culturais em funcionamento na mesma época. ${ }^{57}$

A identidade nacional ancorada no mito gaulês permite, assim, o reencontro com o passado ideal, distante, e que tem na tradição gaulesa, em sua longevidade, a resposta para os dramas atuais da sociedade. Um cartaz editado pelo Front National (figura 1), por ocasião das eleições de 1998 na região de Noisy-le-Sec, lembra a importância do passado e da identidade nacional para o partido (trata-se de uma reprodução estilizada de um outro cartaz produzido para os Chantiers de la Jeunesse (figura 2), durante o Regime de Vichy). ${ }^{58} \mathrm{O}$ affiche do Front traz um velho gaulês, de posse de uma francisca gigantesca, com a mão paternalmente disposta sobre o ombro de um jovem francês, estilo anos 1990. No cartaz se pode ler: “Seja fiel a tua identidade e proteja-a”, constando em destaque, em letras maiúsculas, as palavras "SEJA FIEL", “IDENTIDADE” e "PROTEJA-A”. Em letras menores, abaixo no cartaz,, pode-se ler: "não fique mais isolado, é tempo de nos agruparmos”. 
Associados um ao outro, o ancestral gaulês e o "jovem do Front” se afirmam em uma espécie de casal ambíguo, imposto a nosso olhar: o casal do velho guerreiro e do jovem militante, do pai e do filho, do passado das origens e da "França para os franceses"..$^{59}$

Referência explícita ao cartaz dos Chantiers de Vichy, esta identificação não anunciada se inscreve numa filiação ideológica direta do Front com o movimento petanista. Entre a "France Tojours", do primeiro cartaz, e o "SOIS FIER de ton IDENTITE”, do segundo, uma similar concepção de História, de passado, de valores, de juventude, de propaganda; convergência política e ideológica. Não sem razão é praticamente consenso entre os analistas do Front National a percepção de sua herança política do Regime de Vichy. ${ }^{60}$ É esse mesmo passado que, por meio dos discursos históricos, busca nos gauleses ou nos francos as origens da identidade francesa e se torna pretexto, na modernidade, para a exclusão dos imigrantes, estando na pauta dos debates sobre a identidade nacional. A suposta "origem gaulesa”, como todo elemento definidor das identidades é, aí, fator de inclusão e de exclusão. À homogeneidade histórica e cultural se opõem, nesse campo, as identidades periféricas. A Gália e os gauleses são recuperados obedecendo a interesses políticos, onde se lê uma vontade de união, de diferenciação e de dominação.

a particularidade do sistema de associação da França à Gália é que ele exprime, com variações
segundo os tempos, mas por vezes também simultaneamente, uma reivindicação de identidade
nacional (e, por conseguinte, de particularidade) e uma reivindicação de "primazia” (e, por
conseguinte, de autoridade) sobre os outros povos. ${ }^{61}$

Para Suzane Citron, não há memória gaulesa.

... a origem gaulesa dos franceses é uma elaboração intelectual, hoje, perfeitamente reconhecida, que acompanha os conhecimentos novos ligados ao humanismo dos séculos XV e XVI e que se impõe como "verdade" no quadro da história nacionalista e liberal do século XIX. ${ }^{62}$

A palavra França remete, nos discursos de Jean-Marie Le Pen, ao território e às fronteiras, mas também a uma entidade carregada de uma cultura e História comuns. ${ }^{63}$ Presente nos discursos e na imprensa oficial do Front, a referência à Gália e aos gauleses é sempre manifesta com o intuito de distinguir o francês do não francês. Como essa referência, uma gama de outras, de natureza similar, aludem às mesmas intenções: La france aux français ou La Gaule aux Gaulois; haine anti-gaulois; Gaulois et fier de l'etre, etc. Frases caras a Le Pen e seus partidários, são bem similares àquelas da juventude ultranacionalista do GUD - Groupe Union et Défense - Jeune Résistence e de 
outros grupos direitistas. Como enuncia Le Pen ${ }^{64}$ : "Não sou xenófobo nem racista, mas, sim, francófono ... sou gaulês e a única coisa que temo é que o céu caia sobre minha cabeça, não me assusta o poder”. Para além das referências, analogias e paralelos entre o mundo antigo e a atualidade são bastante comuns na imprensa do partido, seja nas suas matérias, seja em entrevistas e, o que é muito comum, em resenhas quase semanais de livros publicados sobre a Antigüidade (no National Hebdomadaire).

Fundada na genealogia, a nação necessita de ancestrais prestigiosos. Eco de uma França essência, pré-encarnada na Gália, ${ }^{65}$ o discurso do Front National comunga, com demais setores da extrema direita, o investimento nos legados ancestrais; o Front também tem, como outros grupos direitistas, uma juventude nacionalista e racista, orgulhosa de exaltar suas origens gaulesas na internet, em camisetas, prospectos, letras de músicas de seus grupos de RIF - Rock Identitaire Français, etc.

Enfim, ainda que presente nas elaborações identitárias atuais de toda sorte, é no seu uso pelo Front que o mito gaulês tem, hoje, um de seus viéses direitista mais acirrado.

Diversos setores da sociedade francesa se indagam hoje sobre o aumento do número de votos do Front National nas eleições e o do número de aderentes ao partido. O modelo de República autoritária e conservadora que propõe e suas políticas sociais e econômicas funestas e abstratas, calcadas numa concepção hierárquica dos grupos humanos em relação às suas origens, chocam, cada vez mais, os meios especializados.

A sua estigmatização como partido extremista ou a afirmação de sua filiação direta com os fascismos, a condenação quase unânime da qual é objeto pela classe política não faz baixar o nível do voto no frontista, que é, ao contrário, reforçado e diversificado. ${ }^{66}$

A crítica ao projeto ideológico do partido tem sido conduzida a um abandono da demonização como modo principal, senão exclusivo de resposta, buscando, prioritariamente, respostas políticas como a formulação de possibilidades às suas proposições. Os usos que o partido faz do passado nacional permanecem, ainda, por serem estudados. A homogeneidade da identidade francesa almejada e propalada pelo partido também. A quase inexistência de trabalhos a esse respeito evidencia a necessidade dos historiadores, também do mundo antigo, de se inserirem no combate contra o racismo, o elitismo, a xenofobia, o discurso da desigualdade e outras características nefastas do universo frontista. 
De leitura da História muito próxima daquela feita pelo Front National e, por muitas vezes, realizada pelos seus antigos membros, tem-se o círculo de pensamento que se desenvolveu em torno da revista Terre et Peuple, liderado por Pierre Vial (professor de História Medieval na Universidade de Lyon III), antigo membro do Europe-Action e do GRECE. A matriz ideológica de Terre et Peuple e de Vial é formada, então, nas trilhas do pensamento de Dominique Venner e Alain de Benoist.

Tendo abandonado o GRECE, por divergências ideológicas e de estratégias políticas, Vial se junta ao Front National em 1988, e conhecerá uma rápida ascensão na hierarquia do partido. Daí muitas das idéias dos grupos da Nouvelle Droite terem entrado e se desenvolvido no seio do Front. É Vial a criar, em 1995, a revista Terre et Peuple, uma organização de defesa identitária pagã e anticatólica, e, como o Front National, também personalista - centrada na figura de seu líder. Por ocasião da cisão do Front de 1999, Vial restará entre os seguidores de Bruno Mégret, e desempenhará funções muito similares àquelas que desenvolvia no Front, mas, agora, junto ao Mouvement National Républicain. Nos novos quadros de Mégret, Vial encontrará uma convergência muito grande em relação às suas idéias sobre "identidade francesa" e “identidade européia”, ao lado de outros teóricos direitistas como o próprio Mégret, mas, também, Jean-Claude Bardet, Jean-Yves Le Gallou, Pascal-Michel Delmas, Philippe Millau, etc. Reconhecido pelas suas características neopagãs e europeístas, o articulador maior de Terre et Peuple torna-se um dos grandes ícones da extrema direita francesa atual e propugnador do que designa de "guerra étnica”.

Nós caminhamos para uma guerra étnica e esta guerra será total. É necessário, então, preparar mentalmente, psicologicamente, moralmente e psiquicamente o maior número possível de nossos compatriotas nesta perspectiva. ${ }^{67}$

Vial enunciará, no editorial do primeiro número de sua revista, suas principais proposições:

A atualidade acentua, de tempos em tempos, uma evidência: os conflitos étnicos, que sempre existiram e existirão sempre. ... O único remédio é tomar consciência, lucidamente, desta realidade e dela tirar a conseqüência: a cada povo uma terra. É a necessária adequação, a união orgânica entre uma terra e um povo que nos conduziu a escolher, como título desta revista,“Terre et Peuple". ${ }^{6}$

Círculo muito marcado por suas aproximações do hitlerismo, o grupo Terre et Peuple vê, na sociedade francesa e nas sociedades européias, a eminência de um 
confronto maior e decisivo que se anuncia. ${ }^{69}$ Para Guillaume Faye, ${ }^{70}$ um dos principais articulistas da revista,

O século XXI será um século de ferro e de tempestades. Não parecerá com as predições harmoniosas proferidas até os anos setenta. Não será a village global, profetizada por Mac Luban, em 1966, nem o planeta em rede (network planet), de Bill Gates, nem a civilização mundial liberal e sem História dirigida pela ONU, descrita por Fukuyama. Será o século dos povos em competição e das identidades étnicas ${ }^{71}$. E, paradoxalmente, os povos vencedores serão aqueles que restarem fiéis ou retornarem aos valores e realidades ancestrais, quer sejam eles biológicos, culturais, étnicos, sociais, espirituais e que, ao mesmo tempo, sejam mestres da ciência tecnológica.

Autodefinindo-se como comunidade cultural voltada para o "combate cultural identitário”, 72 como o GRECE e o Front National, Terre et Peuple será, também, um grupo muito ligado ao estudo do passado das origens nacionais e terá, na luta contra os imigrantes, os “invasores”, um de seus maiores pressupostos ideológicos. A concepção de identidade do grupo é muito próxima daquela de outros grupos de extrema direita franceses, mas marca-se pela exacerbação de uma idéia orgânica de união entre identidade cultural e identidade étnica, faces de um movimento identitário multiforme e multipolar que anuncia a "primavera dos povos”. ${ }^{73}$ Trata-se de uma identidade fundada sobre a origem, o sangue. Para Vial, ${ }^{74}$ “a dimensão étnica é incontornável quando se fala de identidade. A negação e destruição da identidade é a mestiçagem”; ele crê que os imigrantes não europeus são desenraizados e sofrem as conseqüências disso por parte de um sistema perverso liberal-capitalista. ${ }^{75} \mathrm{~A}$ solução é o retorno às suas terras e seus povos de origem, onde encontrarão o pertencimento, as raízes, as respostas para seus problemas. $^{76}$ Isso permite ao grupo esquivar-se das acusações de racismo. O uso do passado gaulês é, aqui, mais uma vez reivindicado, como retorno à pureza original em uma sociedade racialmente mesclada. No boletim La lettre de Terre et Peuple, de 1998, Vial se indaga: Nossos ancestrais os gauleses? E responde, presente!

Nós queremos que nossas crianças sejam ... gaulesas e orgulhosas de o serem. Que isso agrade ou não às sociedades multicolores, sem corpo e sem alma, contra as quais nós engajamos resistência. Em uma guerra que é necessário chamar por seu nome: uma guerra de liberação nacional.

Vercingetórix e toda sua simbologia empenham, nesse domínio, a verdade, “contra todas as manipulações da História”, ${ }^{77}$, encarnando um mundo celta ao qual se encontram visceralmente ligadas a Europa e a França. Diego Sanromán ${ }^{78}$ observa que "afirmar a identidade gaulesa dos franceses equivale, por um lado, a reconhecer-se 
membro de uma comunidade étnica mais ampla, que se estende por todo o continente europeu”. Sobre Vercingetórix diria Vial:

... é, primeiramente, um personagem histórico do qual é necessário respeitar a autenticidade. Ele aparece ... como a encarnação do mundo celta, à qual nós somos profundamente, visceralmente ligados, pois, é um dos componentes essenciais de nossa Grande Pátria européia. ... Para aqueles que sabem entender, Vercingetórix está sempre presente. Ele chama a Europa celta à batalha, no combate identitário que é, hoje, o jogo decisivo para nossos povos, e o sentido de nosso engajamento. ${ }^{79}$

Como a metáfora da Carte Orange, feita pelo Front, um leitor indignado da revista resume a situação francesa atual da seguinte forma: "Hoje, não é necessário comprar um bilhete de avião para descobrir outras civilizações; podemos, desde já, fazer uma volta ao mundo em 80 estações de metrô". ${ }^{80}$

Ainda no domínio das “metáforas” e dos paralelos, é a longa saga da Europa, chamada por Faye de civilização superior, que este articulista narra à sombra de ilustrações históricas da Antigüidade greco-romana, ${ }^{81}$ em estabelecendo paralelos com o mundo contemporâneo. Para Faye, como Roma ou o Império de Alexandre, a Europa se deixou devorar por seus próprios filhos pródigos, a América e o Ocidente e pelos povos que ela mesma superficialmente colonizou, e vive agora sua quarta idade, que será "para esta civilização herdeira dos fraternos povos indo-europeus, o século fatídico, ... do destino que distribui a vida ou a morte” (7-8). De postura política contrária àquela das diretrizes iniciais da "Nouvelle Droite”, o círculo de Vial propõe um engajamento mais militante, mais aguerrido, chegando, mesmo, a uma espécie de incitação à luta.

Não praticamos nem queremos praticar o intelectualismo, isso não nos impede de realizar uma certa reflexão que chamaremos intelectual, cultural, pouco importa. Mas somos antes de tudo militantes ..., ou seja, combatentes e orgulhosos de nossa postura” ... O combate intelectual e o combate político são inseparáveis. ... Trata-se simplesmente de unir a reflexão à ação, cuidando sempre da qualidade, da intensidade, da profundidade da reflexão ... tomar consciência das próprias raízes é necessário mas não é suficiente. Falta, contudo, lutar contra aqueles que querem destruí-las ... ${ }^{82}$

No campo do engajamento, das relações entre o pensamento e a ação, Terre et Peuple é de uma proposta muito mais combativa que uma de suas principais matrizes ideológicas, aquela que vem de Dominique Venner. O discurso de crise social é extremamente semelhante àquele do Front National. Para a "guerra cultural”, a "guerra étnica”, Vial responde (1996): “é necessário uma armada. Nós temos a ambição de criar esta armada. Uma armada que deve ser uma comunidade de trabalho, de combate”. 
Defensor de uma espécie de enraizamento cultural e de uma fidelidade identitária, o círculo tem a História, desde os gregos e romanos, como testemunha dos fracassos e derrocadas das sociedades multiculturais. O exemplo do Império romano do Ocidente, como em outros grupos direitistas, é o mais utilizado a esse respeito. Com os "olhos no passado", um articulista vê que o futuro trará, "sem nenhuma dúvida, explosões previsíveis; na Índia entre os hindus e muçulmanos, no Brasil com a população mais mestiça do mundo, e, talvez, em nosso próprio país”. ${ }^{83}$

Para enfrentar esse futuro nefasto de "guerras étnicas" Faye vê a necessidade da França de cultivar sua fidelidade identitária e sua ambição histórica, tudo resumindo em uma grande metáfora num artigo intitulado “ $\mathrm{XX}^{\mathrm{e}}$ siècle $-L$ 'Europe, un arbre dans la tempête" ${ }^{84}$ Composta por raízes, tronco e folhagens - gérmen, soma e psique, as raízes representam a alma ancestral e o futuro do povo e, por serem destinadas às novas gerações, toda mestiçagem é vista como uma apropriação indevida e uma traição; o tronco é a expressão cultural e física do povo, alimentada pelas raízes, e a folhagem, frágil e bela, "é a civilização, a produção e a profusão das novas formas de criações ... a razão de ser da árvore”, sempre ameaçada pelas intempéries. A Europa vive, para Faye, uma ameaça por dois vírus: “o do esquecimento de si, da morte interior e aquele da abertura ao outro". ${ }^{5}$ Para a sobrevivência da Europa dos povos, com etnia e alma coletivas $^{86}$ é imprescindível o sentimento comunitário ${ }^{87}$ europeu. Aí não deve faltar $a$ esperança de uma resistência gaulesa. ${ }^{88}$

A História da Antigüidade está muito presente nas justificativas legitimistas desses grupos de direita, numa espécie de remake do Nacional Socialismo; os elementos de referência não são poucos. Apesar das proximidades, é quase unânime entre os especialistas a convicção de que os movimentos direitistas desta vertente não constituem um “ressurgimento" do Nazismo e do Fascismo, contudo, suas aproximações da Antigüidade são muito similares àquelas levadas a termo por esses regimes. É necessário procurar se aperceber, tanto num momento quanto no outro, de que escolhas da Antigüidade se tratam. Importante é perscrutar, hoje, como a França, pelo viés das extremas direitas, recria, fabrica, seu passado indo-europeu, grego, romano, etc.

No momento em que os muros caíram, onde os países do leste retornam, onde se coloca novamente a questão da identidade européia, de sua cultura, de suas políticas, no momento onde a hidra do racismo e da xenofobia tem cabeças que atacam, reclamando sua herança da Grécia ou da herança indo-européia. ${ }^{89}$ 
Não é inconveniente nos perguntarmos que lugar a Antigüidade ocupa em nossas sociedades.

\title{
Agradecimentos:
}

Agradeço à Professora Margarida Maria de Carvalho o convite para apresentar esse trabalho para publicação. Agradeço também a Pedro Paulo Abreu Funari (Universidade Estadual de Campinas) e a Laurent Olivier (Université de Paris I Sorbonne) as importantes contribuições. A responsabilidade pelas idéias, contudo, é exclusivamente minha.

SILVA, Glaydson José da.The Ancient world under contemporary lens: right wing extremists in France in 80s and 90s, or, about the instrumentalism of Antiquity. Historia, São Paulo, v. 26, n. 1, p 98-118, 2007.

\begin{abstract}
This work analyses the uses of the ancient world by right-wing French extremists as means to establish comprehensions of the contemporary world, aiming at the legitimization of rights derived from origin. It proposes a reflection upon the role of the past in relation to the strategy games and identity affirmations based on the instrumentalization carried out by analyzed groups (GRECE, Front National and Terre et Peuple). This work was developed considering the premise that the Past, its writings and readings are powers and generate powers.
\end{abstract}

Keywords: Instrumentalization of Antiquity, Right-wing Extremists, Uses of the Past

Artigo recebido em 04/2007. Aprovado em 06/2007.

\section{NOTAS}

\footnotetext{
* Pós-doutorando do Departamento de História da Unicamp. Diretor Associado do Centro do Pensamento Antigo Clássico, Helenístico e de sua Posteridade Histórica.- Instituto de Filosofia e Ciências Humanas Unicamp -13081-970 - Campinas/SP. Bolsista Fapesp. E-mail: sglaydson@hotmail.com

${ }^{1}$ SCHIAVONE, Aldo. La Histoire brisée. La Rome antique et l’Occident moderne. Paris: Belin, 2003.

2 MacDONALD, W. A. Archaeology in the 21st century: six modest recommendations, Antiquity, 65, p.829-839, 1991.

${ }^{3}$ FUNARI, Pedro Paulo Abreu. Antigüidade Clássica - a história e a cultura a partir dos documentos. Campinas: Edunicamp, 2002. p.30.

${ }^{4}$ DROIT, Roger-Pol. Les Grecs, les Romains et nous. L'antiquité est-elle moderne? (Org.). Paris: Le Monde Editions, 1991. p.7.

${ }^{5}$ SIRINELLI, Jean-François. (Org.) Histoire des droites en France. Paris: Gallimard, 1992. t.I, p.IV.
} 
${ }^{6}$ MILZA, Pierre. L'Europe en chemise noire: les extrêmes droites européennes de 1945 à aujourd'hui. Paris: Fayard, 2002. p.7.

7 DUBUISSON, Michel. Réflexions sur l'actualité de l'Antiquité gréco-romaine. In: Histoire de l’Antiquité. Orient, Grèce, Rome. Liège, 2001.

${ }^{8}$ MILZA, Pierre. Op. cit., p.7.

${ }^{9}$ Idem, p.17.

${ }^{10}$ Idem.

${ }^{11}$ TAGUIEFF, Pierre-André. Sur la Nouvelle droite. Paris: Descartes e Cie, 1994. p.9.

${ }^{12}$ MILZA, Pierre. Op. cit., p.192-193.

${ }^{13}$ Idem, p.193.

${ }^{14}$ VENNER, Dominique. "Sur un nouveau phénomène revolutionaire” - Défense de l’Occident, 26-11, 1962.

${ }^{15}$ VENNER, Dominique. Europe-Action, 39, mars 1966, p.8.

16 TAGUIEFF, Pierre-André. Op. cit., p.V.

${ }^{17}$ MILZA, Pierre. Op. cit., p.198.

18 TAGUIEFF, Pierre-André. Op. cit., p.9-106.

${ }^{19}$ BENOIST, Alain de. Vue de droite. Paris: Éditions Copernic, 1977. p.16.

${ }^{20}$ MILZA, Pierre. Op. cit., p.199.

${ }^{21}$ BENOIST, Alain de. Europe-Action, n.36 décembre 1965. p. 9.

${ }^{22}$ BENOIST, Alain de. Comen peut-on être païen? Paris: Albin Michel, 1981. p.251.

${ }^{23}$ DUMOULIN, Olivier Histoire et historiens de droite. In: SIRINELLI, Jean-François (Org.). Histoire des droites en France. Cultures. Paris: Gallimard, 1992. p. 327-398.

${ }^{24}$ BENOIST, Alain de. Op. cit, 1977, p.10.

${ }^{25}$ RAPPORT Sur Le Négationnisme Et Le Racisme A L’université Lyon 3. Lyon: Conseil Lyonnais pour le respect des Droits, 2002.

26 SERGENT, Bernard. Penser et mal penser les indo-européens. Note critique. Annales Economie, Société civilisation, 4, p.669-681, juillet-août 1982.

27 DEMOULE, Jean-Paul. Destin et usages des Indo-Européens. Mauvais temps, numéro 5, juillet 1999. Disponível em: http://www.anti-rev.org/textes/Demoule99a/index.html

${ }^{28}$ OLENDER, Maurice. Georges Dumézil et les usages “politiques” de la préhistoire indo-européenne. In: DROIT, Roger-Pol. Les Grecs, les Romains et nous. L’antiquité est-elle moderne? (Org.). Paris: Le Monde Editions, 1991. p. 208.

${ }^{29}$ MILZA, Pierre. Op. cit., p.202.

${ }^{30}$ BENOIST, Alain de. Op. Ccit.1981, p.251.

${ }^{31}$ Idem, p.203.

${ }^{32}$ VIAL, Pierre. Editorial. Élements, 33, février-mars1980, p.10.

${ }^{33}$ MILZA, Pierre. Op. cit., p.203.

${ }^{34}$ BENOIST, A. de, CHAMPETIER, C. La Nouvelle Droite de l’an 2000. Élements, 94, Février 1999.

${ }^{35}$ TAGUIEFF, Pierre-André. Op. cit.

${ }^{36}$ MILZA, Pierre. Op. cit., p.207-210.

${ }^{37}$ WINOCK, Michel. Le Front National: portrait historique d'un parti d'extrême droite. L'Histoire, Paris, n. 219, mars 1998.

${ }^{38}$ Idem.

${ }^{39}$ APPARU, Jean-Pierre. La droite aujourd'hui. Paris: Albin Michel, 1978. p.176; MILZA, Pierre. Op. cit., p.18-19.

${ }^{40}$ ORFALI, BIRGITTA. L'adhésion au front national. De la minorité active au mouvement social. Paris: Éditions Kimé, 1990.

${ }^{41}$ CHEBEL D’APPLOLONIA , Ariane. L'extrême droit en France - de Maurras a Le Pen. Paris: Complexe, 1999; CUMINAL, Isabelle (et al.). Le pen, les mots. Analyse d'un dsicours d'extrême droite. Paris: Le Monde Editions, 1997. p.12.

${ }^{42}$ LE PEN, Jean Marie. Dossier Pour un vrai code de la nationalité. National Hebdomadaire, n.140 Semaine du 26 mars au 1er avril 1987. p.10.

43 Texto publicado no National Hebdomadaire. Semaine du 03 au 09 août 1995, n.576, p.11.

44 KASTORYANO, Riva. Nationalité et citoyenneté en Allemagne aujourd'hui. Vingttième Siècle, 70, p.3-17, 2001.

${ }^{45}$ LE PEN, Jean Marie. Politique culturelle. Discours de Jean Marie Le Pen, Avignon, 2002.

${ }^{46}$ ORFALI, BIRGITTA. Op. cit., p.152.

${ }^{47}$ BARRAL, Pierre. La terre. In: SIRINELLI, Jean-François (Ed.). Histoire des droites en France. Paris: Gallimard, 1992. t.III - 49-70, p.67. 
${ }^{48}$ Excerto de um discurso de Le Pen em La Trinité, citado em: CUMINAL, Isabelle (et al.). Op. cit., p. 96.

${ }^{49}$ LE PEN, Jean Marie. Op. cit., 1987, p.10.

${ }^{50}$ LE PEN, Jean Marie. Editorial , Identité, 1991, n.1-2.

${ }^{51}$ ORFALI, BIRGITTA. Op. cit., p.159.

52 LORAUX, Nicole. La démocratie à l’épreuve de l'étranger. In: DROIT, Roger-Pol. Les Grecs, les

Romains et nous. L’antiquité est-elle moderne? (Org.). Paris: Le Monde Editions, 1991. p.177.

${ }^{53}$ Idem, p.189.

${ }^{54}$ CUMINAL, Isabelle, (et al.). Le pen, les mots. Analyse d'un dsicours d'extrême droite. Paris: Le Monde Editions, 1997. p.11.

55 SILVA, Glaydson José da. Antigüidade, Arqueologia e a França de Vichy: usos do passado. Campinas, 2005. Tese de doutorado - Unicamp.

56 THIESSE, Anne-Marie. La creation des identities nationales. Europe XVIIIe siècle. Paris: Seuil, 1999. p.21.

${ }^{57}$ BACZKO, Bronislaw. Sentiment monarchique et “gallicité”. In: VIALLANEIX, P., EHARD, J. Nos ancêtres les gaulois - Actes du Colloque International de Clermont-Ferrand. Clermont-Ferrand, Faculté des Lettres et Sciences Humaines de l’Université de Clermont-Ferrand II, Nouvelle série, Fascicule 13, 1981. p.17.

${ }^{58}$ OLIVIER, Laurent. Vichy, Le Pen et les gaulois. De la Révolution National au Front National. Les nouvelles de L’Archéologie, 72, p.31-35, 1998.

${ }^{59}$ Idem.

${ }^{60}$ CAMUS, Jean-Yves. Le Front National - Histoire et analyses. Paris: Editions Laurens, 1997, p.157161.

${ }^{61}$ DUBOIS, Claude Gilbert. Nos ancêtres les Gaulois - le développement d'un mythe des origines nacionales au 16e siècle. In: VIALLANEIX, P., EHARD, J. Nos ancêtres les gaulois - Actes du Colloque International de Clermont-Ferrand. Clermont-Ferrand, Faculté des Lettres et Sciences Humaines de l’Université de Clermont-Ferrand II, Nouvelle série, Fascicule 13, p.20, 1981.

${ }^{62}$ CITRON, Suzane. Le Myythe national. L’histoire de France en question. Paris: E.D.I., 1991. p.103104.

${ }^{63}$ CUMINAL, Isabelle, (et al.). Op. cit., p.98.

${ }^{64}$ LE PEN, Jean Marie. Entrevista a Jean-Marie Le Pen. Jornal digital La Vanguardia.es por J. Ramón González Cabezas, en 01/02/2004.

${ }^{65}$ CITRON, Suzane. La construction du mythe national. In: CITRON (et al.). Histoire de France mythes et réalités: quelle place pour les peuples et les minorités? Toulouse: Érès, 1995. p.17-19.

${ }^{66}$ CAMUS, Jean-Yves. Op. cit., p.13.

${ }^{67}$ VIAL, Pierre. La Leerte de Terre et Peuple, 4, 1995.

${ }^{68}$ VIAL, Pierre. Planton notre drapeau. Terre et Peuple, n.1,1999, p.1.

${ }^{69}$ VIAL, Pierre. Le mouvement identitaire, Terre et Peuple, n.1, 1999a, p.1.

${ }^{70}$ FAYE, Guillaume. L’Europe, un arbre dans la tempête.. Terre et Peuple, n.2, 1999, p.7.

${ }^{71}$ Grifo no original.

${ }^{72}$ VIAL, Pierre. Op. cit., 1999, p.1.

${ }^{73}$ VIAL, Pierre. Tere et Peuple, n. 2, 1999b, p.1.

${ }^{74}$ VIAL, Pierre. Oser! Terre et Peuple, n.5, 2000, p.1.

${ }^{75}$ VIAL, Pierre. Europe, notre patrie! Terre et Peuple, n.6, 2000a.

${ }^{76}$ VIAL, Pierre. Appel pour un communitarisme européen, Terre et Peuple, n.19, 2004, p.1.

${ }^{77}$ VIAL, Pierre. Vercingétorix - Le Celte. Terre et Peuple, n. 7/8, 2001, p.7-8.

${ }^{78}$ SANROMÁN, Diego. La nueva derecha en Europa: una revisión crítica. Acción Chilena. Disponible en: http://www.accionchilena.cl/Doctrina/ciberfascismo.htm

${ }^{79}$ VIAL, Pierre. Op. cit., 2001, p.32.

${ }^{80}$ ROLLINAT, Jean-Claude. En France comme ailleurs, une terre pour un peuple, un peuple sur sa terre. Terre et Peuple, n.7/8, p.7, 2001.

${ }^{81}$ FAYE, Guillaume. Op. cit., p.7-9.

82 SANROMÁN, Diego. La nueva derecha en Europa: una revisión crítica. Acción Chilena. Disponible en: http://www.accionchilena.cl/Doctrina/ciberfascismo.htm

${ }^{83}$ CHRISTELE, Louis. La societé multi-culturelle à l'épreuve de l'Histoire. Terre et Peuple, n.1, p.2829, 1999.

${ }^{84}$ FAYE, Guillaume. Op. cit., p.7-9.

${ }^{85}$ Idem, p.8.

${ }^{86}$ VIAL, Pierre. Il faut penser à notre ame. Terre et Peuple, 172003. 
${ }^{87}$ VIAL, Pierre. Face au grande suicide. Terre et Peuple, n.18, 2003a, p.1.

${ }^{88}$ VIAL, Pierre. Op. cit., 2004.

${ }^{89}$ DROIT, Roger-Pol. Op. cit., p.7. 